\title{
LA IDENTIFICACIÓN DE LAS PERSONAS EN EL ALTO IMPERIO ROMANO: PROBLEMÁTICA ANTIGUA Y ACTUAL*
}

\author{
IDENTIFICATION OF PEOPLE IN THE HIGH ROMAN \\ EMPIRE: AN OLD AND CURRENT PROBLEM
}

\section{ALEJANDRO BANCALARI MOLINA**}

\section{RESUMEN}

El artículo tiene como propósito central estudiar la libertad de circulación de las personas en el alto imperio romano y cómo eran individualizadas y controladas. Asimismo, se profundizará la noción de frontera, los mecanismos de control interno y las diferentes formas de identificación tanto del ciudadano como de los extranjeros y de los otros miembros del orbe romano.

Palabras clave: Imperio, Roma, circulación, gente de paso, identificación, fronteras, controles.

\section{ABSTRACT}

The main purpose of this article is to study the freedom of movement of people in the high Roman Empire and the way they were identified and controlled. In addition, the notion of border, the internal control mechanisms and the different forms of identification of citizens, foreigners and other members of the Roman world will be delved into.

Keywords: Empire, Rome, movement, people in transit, identification, borders, controls.

Recibido: 23.12.16. Aceptado: 23.01.17.

\footnotetext{
* Este artículo forma parte de un proyecto Fondecyt titulado "La circulación de las personas al interior del imperio romano: desde Augusto a Alejandro Severo", Nº 1140467.

** Doctor en Historia por la Universidad de Pisa, Italia. Profesor Titular de Historia Antigua, Departamento de Ciencias Históricas y Sociales, Universidad de Concepción. Concepción, Chile. Miembro de Número de la Academia Chilena de la Historia. Correo electrónico: abancala@udec.cl.
} 


\section{PROBLEMATIZACIÓN}

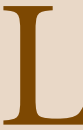

A HISTORIA ACTUAL, particularmente los fenómenos acontecidos en la Eurozona debido a los movimientos migratorios, ya sea para superar y cambiar sus condiciones de vida, ya sea por las guerras civiles como por los refugiados, hacen del tema de la identificación de personas un problema complejo y significativo. Los europeos, a partir de la primavera árabe de 2011, han sufrido un proceso de inmigración masiva a través del Mediterráneo, en forma especial en la península balcánica e italiana. Las autoridades -en su mayoría- argumentan que por razones humanitarias es necesario aceptar a los inmigrantes; otros, y parte de la población civil, consideran que debe filtrarse, ordenarse y detenerse el proceso migratorio. Vale decir, poseer los protocolos y mecanismos adecuados para un sistema de control e identificación de las personas e individuos. Máxime si son extranjeros y pretenden arraigarse ilegalmente.

La Unión Europea está padeciendo esta realidad preocupante en sus fronteras. Surge así el dilema de la seguridad, el carácter estratégico y defensivo de los confines territoriales, en contraposición a las situaciones humanitarias. Distinto es el caso de su Espacio Schengen ${ }^{1}$, donde los ciudadanos europeos pueden circular y transitar libremente. Acuerdo que hoy en día está cuestionándose, con polémicas, controversias, dicotomías e incluso negaciones del propio espacio. Surge naturalmente el problema de cómo estas situaciones actuales acontecidas en el continente europeo puedan servir para reestudiarlas en el imperio romano y viceversa. Producir un diálogo fecundo, comparativo y aclaratorio entre lo antiguo y lo contemporáneo. En el caso romano los ciudadanos y peregrinos (extranjeros) se desplazaban en forma libre; interesa entonces comprender globalmente cuál fue el

${ }^{1}$ El Espacio Schengen (Schengenland) es un acuerdo firmado en Luxemburgo y que entró en vigor en 1995. El gran objetivo consistía en terminar progresivamente el control de las fronteras entre los países signatarios y que los ciudadanos europeos pudieran circular en forma libre, sin la necesidad de mostrar el pasaporte. Se suprimen entonces las fronteras internas y se crea una mayor y una exterior, donde se efectúan los controles de entrada y salida de los miembros de esa zona comunitaria. Son más de quinientos millones de habitantes que se mueven y circulan con entera libertad al interior de sus territorios. El acuerdo está constituido por todos los países miembros de la Eurozona, excluyendo a Gran Bretaña e Irlanda, los cuales no permiten suprimir sus controles aduaneros, pero sí cooperar en los procedimientos comunes policiales, judiciales y en la protección interior de los países adherentes. Si bien estados como Bulgaria, Rumania y Chipre forman parte del convenio, tampoco suprimen totalmente los controles fronterizos internos. El Espacio Schengen, además de la movilidad de las personas, persigue la integración de los miembros europeos. Véase, sobre el acuerdo, D. Bigo (1998, pp. 148-164); F. Cerutti y E. Rudolph (2002, pp. 246-247). 
sistema de identificación o certificación de cada sujeto. Este fenómeno de la antigua Roma podrá ayudarnos en una visión de conjunto y como antecedente del complejo escenario de la realidad europea.

Es unánimemente aceptado que el mundo romano en el alto imperio conformó una communitas y una ecúmene mediterránea ${ }^{2}$ integrada y con libertad de desplazamiento de sus habitantes. Las fuentes son claras y explícitas al mostrar un mundo abierto, transitable, con posibilidad para viajar libremente de un lugar a otro. En el fondo, un orbis pacificado e interconectado ${ }^{3}$. De esta forma, los miembros del imperio ¿se movilizaron ${ }^{4}$ a entera voluntad o existió algún tipo de control interno y documentación que acreditara la identificación de ellos?

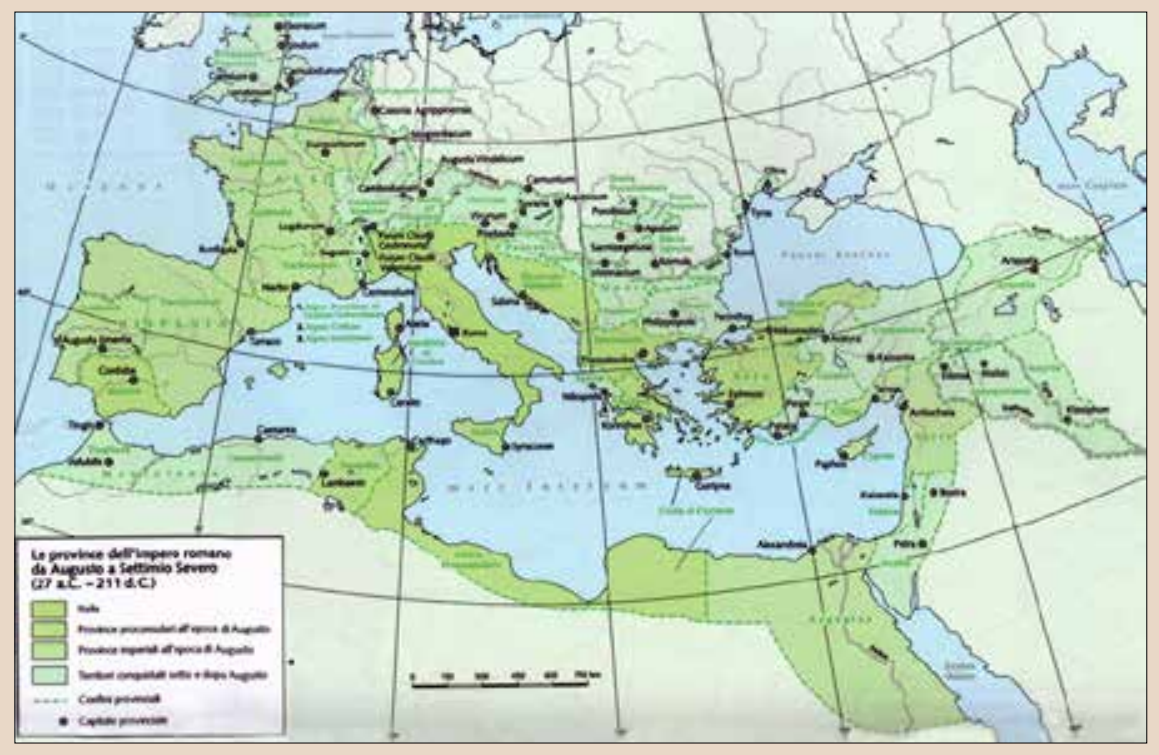

El imperio romano en la época de los Antoninos (S. II d.C.). Fuente: C. Letta e S. Segenni (eds.), Roma e le sue province. Dalla prima guerra punica a Diocleziano.

\footnotetext{
${ }^{2}$ La generalizada noción de un imperio multidimensional, plurilingüístico, multirracial e integrado, entre otros autores, A. Garzetti (1974); F. Millar (1977); G. I. Luzzatto (1985); M. Grant (1994); D. Noy (2002); A. Bancalari (2007); A. Giardina et F. Pesando (a cura di) (2012).

${ }^{3}$ Algunas fuentes que muestran el tránsito de las personas al interior del orbe romano: Tácito, Annales, I, 9, 5; Elio Aristides, Elogio a Roma, XXVI, 61-62; Tertuliano, Sull' anima, 30; Ireneo, Contra los herejes, 4, 30, 3; Pseudo Arístides, Discorso all' imperatore, 37.

${ }^{4}$ La terminología latina para expresar la movilidad y circulación de las personas utilizó las siguientes expresiones: adventor, el visitador; el que viene de lugares lejanos y pasan por la ciudad. Diverso a hospes, huésped público; el que es alojado; pero también al forastero y viajero que se instala de manera provisoria en alguna parte, en oposición al inquilinus (que viene de lejos y vive arrendando una habitación o casa en forma prolongada). En menor medida, se utilizó en un sen-
} 
Por cierto, ¿se necesitaba algún permiso especial y/o un tipo de individualización? ¿Existió una política de discriminación, de intolerancia o más bien se plasmó una integración? ¿Existieron impostores con cambios de identificación? ¿Fue recurrente el fenómeno del travestismo? ¿Cuáles fueron los procedimientos administrativos, los documentos emitidos y los elementos necesarios que permiten validar una identificación? ¿Qué categorías de población eran controladas por las autoridades? ¿Existió realmente un control social? ¿Hasta qué punto esta gente de paso eran grupos de presión y podían atentar contra el orden público? ¿Qué sucedió con las elites exteriores al imperio? ¿Existieron dispositivos restrictivos y represivos respecto de los inmigrantes, habiendo limitación y control social? ¿Debían pagar algún impuesto aduanero y/o fronterizo o en la entrada de cada territorio y ciudad? ¿Roma tuvo el carácter de "ciudad abierta"? Estas son parte de las interrogantes que debemos dilucidar 5 .

\section{FRONTERAS EXTERNAS}

En el mundo romano, las fronteras tuvieron un carácter polisémico y variado, no solo fueron concebidas en función de líneas o murallas de demarcación territorial entre un Estado y otro, también tuvieron un carácter administrativo, geográfico, militar y, sobre todo, cultural (Forni, 1988, pp. 272-294; Cunliffe, 1994, pp. 1257-1292). Esto significa un conjunto de formas e identidad en contraposición a otra (alteridad). Es la dicotomía Romanitas versus Barbaria (externae nationes) y la diferenciación de quienes se encontraban al interior o exterior de la frontera.

Es difícil determinar en forma exacta si existió un riguroso control militar y/o policial en los límites del imperio. Las fuentes son equívocas, presentan diversidad de casos. No obstante esto, al parecer el ingreso al interior del orbe romano no era libre (Valditara, 2015, p. 51). Existió una política de control fronterizo, de permisos especiales, salvoconductos, hospitalidad

tido más general, viator (viajero). Todas estas expresiones representan a "gente de paso", que no se encuentran en su "domicilio legal”. Para una profundización de la nomenclatura, cfr. C. Ricci (2005, pp. 6-8); C. Moatti (2007, pp. 80-81).

${ }^{5}$ El tema del desplazamiento y circulación de individuos y grupos y sus identificaciones al interior del mundo romano, es un argumento complejo y de mucha actualidad, con perspectivas diversas. Entre los estudios más relevantes de la problemática encontramos: E. Frézouls (1989, pp. 123-138); M. Sordi (ed.) (1994); Y. Modéran (1994, pp. 337-397); C. Moatti (2000/2, pp. 925958); D. Noy (2002, pp. 53-84); D. Whittaker (2004, pp. 127-153); F. Marco Simón, F. Pina Polo, J. Remesal Rodríguez (eds.) (2004); C. Ricci (2005); J.M. Lassère (2006, pp. 57-92); A. Barbero (2006); C. Moatti, W. Kaiser, C. Pébarthe (eds.) (2009). 
y diversas barreras. En fin, la tarea del historiador en estos estudios, según Moatti et Kaiser (2007, p. 10), es "determinar cuándo la frontera es económica, social o territorial y si el control es fiscal, penal o identitario". Muchos de los diversos pueblos que trataron de cruzar los confines imperiales lo hacían por motivos económicos y comerciales, esencialmente los mercaderes ${ }^{6}$. En síntesis, si bien existían formas de fiscalización para aquellas personas que salían o ingresaban, surgió un sistema flexible de permisos y controles fronterizos (Barbero, 2006, p. XIV). No una rigidez absoluta ni monolítica en los casos de emigración, pero tampoco una libertad total para quienes deseaban asentarse al interior del orbe romano. Existió por cierto una suerte de inmigración tanto legal ${ }^{7}$ como ilegal. Sin embargo, Roma intentó llevar a la práctica diferentes protocolos y mecanismos de control fronterizos y aduaneros, similares a los de nuestros tiempos modernos.

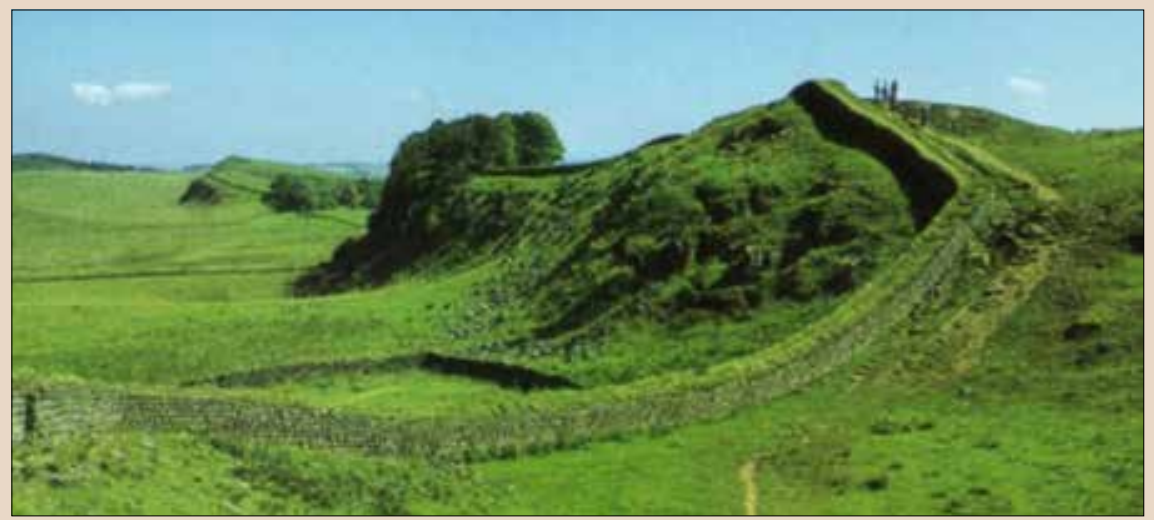

Panorámica del muro defensivo de Adriano, el límite norte del imperio en Britania.

\footnotetext{
${ }^{6}$ Algunos casos extraídos de las fuentes serían: de acuerdo con Tácito (Germania 41), la tribu de los hermunduros mantenía relaciones comerciales con los romanos, no solo en el confín actual, sino al interior de la provincia de Recia. Estos germanos pudieron entrar al territorio sin vigilancia (sine custode), desplazarse libremente, comprar y vender lo que deseaban. Se trata de un ejemplo excepcional y privilegiado, no fue uniforme en todos los confines. Por otra parte, las diferentes tribus germanas estaban autorizadas a comerciar al interior del imperio solo con escoltas y guarniciones y en lugares autorizados y delimitados. Igualmente, Marco Aurelio prohibió que los cuados fuesen a los mercados que se encontraban en suelo romano (Dión Casio, Historia Romana, LXXII, 11,3). Su hijo Cómodo limitó una vez por mes, en un único lugar y bajo vigilancia, los encuentros entre mercaderes romanos y germánicos (Dión Casio, LXXIII, 2, 4). También en el limes oriental con los partos, Caracalla desarrolló una política comercial (Herodiano, Historia del imperio romano, IV, 10, 4; Dión Casio, LXXVIII, I, 1).

${ }^{7}$ Consiste en un control en las fronteras programado con registros, horarios, documentación, identificación, salvoconductos y otros que forman parte de un "aparato burocrático institucionalizado", tal como ha sucedido con los estados modernos y en la actualidad.
} 
Sin duda, el mundo romano plantea problemas y casos diversos y existen fuentes irrefutables para observar los diferentes controles y pruebas aduaneras. Muchas de ellas no fueron sistemáticas, ni permanentes. En algunos sectores las hubo más rígidas, en la zona oriental con los partos; en otros, más variables, como en el limes africano y muy permeables en la zona renana-danubiana, por lo que algunos estudiosos han planteado la idea de "frontera bisagra y móvil"s. Este aspecto es de sumo interés al considerar que el Rin y el Danubio no fueron confines cerrados ni fijos, sino por el contrario, puntos de encuentro de comercialización e integración (Lassandro, 1986, pp. 153-159). Con esta concepción cambia la tesis tradicional de Edward Luttwak (1976, pp. 175-181), sobre la "estrategia global del imperio" con límites especialmente científicos, lineales y como verdaderas murallas divisorias. Ciertos estudios presentan una noción del limes, entendido como una bisagra, un puente, un punto de contacto para intercambio de todo tipo, que une, más que una frontera en calidad de muralla concreta y defensiva (Cracco Ruggini, 1993, p. 359), que tiene como propósito central dividir y marcar la diferencia entre romanidad y barbarie. Para otros no era un sistema perfecto de defensa, sino más bien una "frontera ética", en el sentido y en la simbología romana de que debido a sus valores espirituales y civilizadores el imperio romano era superior al mundo exterior (Alföldy, 2009, p. 77). Los límites no deben ser analizados como confines naturales, más bien, los ríos permiten la comunicación y los intercambios; unen e integran a sus habitantes, en vez de separarlos. Concordamos con Charles Whittaker (2000, pp. 462-482) cuando señala que las fronteras romanas "no eran barreras políticas, sino definiciones sociales, culturales y morales de la comunidad y de la alteridad; algo muy opuesto a los límites fijos de la etnicidad y territorialidad surgidas con el Estado-Nación". Se presenta una diferenciación clara y categórica.

\section{IDENTIFICACIÓN}

En los desplazamientos al interior del orbe romano, el tema de la identificación de las personas (concebidas en el rol social del individuo), es un problema complejo y de difícil precisión. De partida, a diferencia de nues-

\footnotetext{
${ }^{8}$ Entre estos estudios, B. Isaac (1992); P. Trousset (1993); F. Millar (1993); E. Lo Cascio (1995); C. R. Whittaker (2000).
} 
tro tiempo, no era obligatorio para los ciudadanos y miembros del imperio llevar consigo un documento que acreditara su identificación (Pecchi, 2013, pp. 39-46). De ahí que la autenticidad o certificación de cada persona no se probaba con el solo hecho de mostrar un pasaporte o carnet de identidad, ya que existieron múltiples formas de identificación. La estudiosa de la Universidad de California, Claudia Moatti (2004, pp. 5-6), las clasifica de acuerdo a variados criterios: podían ser reconocimientos y señales físicas particulares, como cabellos, tatuajes, cicatrices e incluso la huella del pie en la tierra; la firma, que supone un grado de alfabetización; la declaración, que puede ser simple o bajo juramento; categoría de signos, vestimenta ${ }^{9}$, zapatos, anillos; los objetos figurados, sellos y téseras; otros documentos públicos o privados, como salvoconductos, certificados de permisos militares y diplomas militares, cartas de recomendaciones, negociaciones diplomáticas y, finalmente, la residencia en algún lugar. Del mismo modo, otra forma de identificación utilizada fue la tesserae hospitales, es decir una carta de hospitalidad que una familia confería a otra para ser invitada y visitada por alguna actividad de tipo familiar, social o religiosa. Muchas de estas tessera hospitalis se otorgaron entre familias de Roma, la península Itálica y la Hispania (Le Roux et Tranoy, 2006, pp. 323-336). Todas aquellas eran categorías y signos de identidad. En cierta medida, el imperio utilizó diversos mecanismos de control, restricción e identificación (Moatti et Kaiser, 2007, pp. 9-17) para todas las personas e individuos que se movilizaban y circulaban en su interior. Tuvieron además un derecho: ius gentium ${ }^{10}$. No olvidemos que la cultura grecorromana fue una sociedad "cara a cara", de mirarse, donde se favorecía la cercanía y control de proximidad, oficio que en Roma desarrollaron los vicomagistri y los prefectos (custodia urbis).

\footnotetext{
${ }^{9}$ La vestimenta era clave, en especial la toga, como el traje formal de los ciudadanos romanos, que significaba un reconocimiento social (estatus) y de identificación, diverso a los extranjeros y esclavos.

${ }^{10}$ Expresión que designa los usos comunes a todas las "personas civilizadas" (Gayo, Instituciones, I, 1) o al derecho aplicado a las relaciones con los "peregrinos protegidos" (Gayo, Instituciones, III, 93). El ius gentium en calidad de primer derecho internacional.
} 

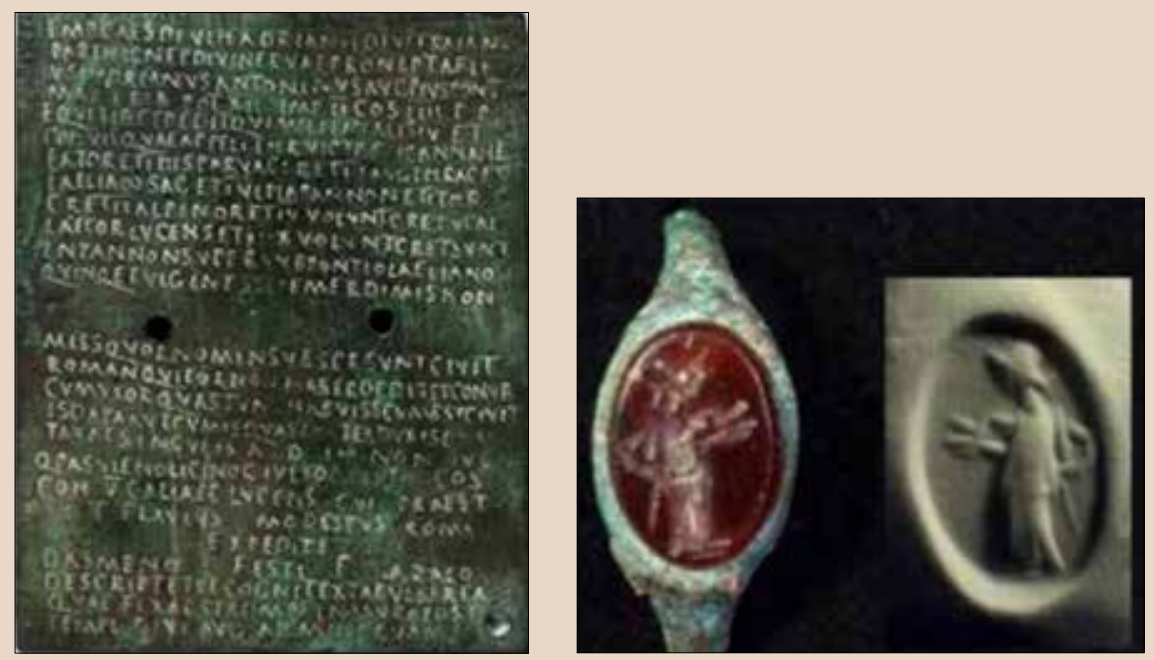

Diplomas, anillos, sellos, como formas de identificación. Fuente: V. Mancini, L'identità romana.

Ahora bien, surge otra problemática: ¿Existió verdaderamente en la antigua Roma el pasaporte, tal como lo conocemos en la actualidad o algo similar que garantizara la autenticidad del sujeto? (Purpura, 2002, pp. 131$155)^{11}$. Si entendemos el pasaporte como un método de identificación personal, una disposición legal o medio, un documento de reconocimiento para salir o entrar de un territorio, un instrumento para diferenciar en las fronteras a los potenciales enemigos, no lo hubo en toda la antigüedad, ni tampoco en Roma. Es una creación a partir de los estados modernos europeos, en especial con la conformación de la idea del Estado-Nación. También se constituyó como una limitación de un ordenamiento estatal a la libertad individual. Originalmente, esta acreditación en calidad de licencia se le concedía a las "naves" que atracaban en los puertos.

Tácito nos transmite que Germánico -siendo senador en el año 19 d.C.partió hacia Egipto a fin de recorrer el territorio y conocer sus antigüedades. Viajó sin escolta militar, con atuendos simples, al estilo de los griegos. El emperador Tiberio "lo increpó duramente, porque contra lo establecido por Augusto, había entrado en Alejandría, sin autorización del príncipe"12;

\footnotetext{
${ }^{11}$ Este autor considera que el pasaporte (en el sentido moderno del término) era una especie de "permiso nominativo" o concesión. Literalmente, significaba "pasar por la puerta" de la muralla de una ciudad.

${ }^{12}$ Tácito, Annales, II, 59.
} 
por tanto, sin un permiso especial. ¿Qué significaba este permiso? Augusto -entre otros misterios de su dominación-consideraba a Egipto como patrimonio suyo, era un caso aparte y prohibió que entraran senadores y caballeros ilustres "sin su autorización"13. El problema mayor fue que Octaviano, después del 29 a.C., al tomar el control de Egipto, mantuvo una presunta idea antisenatoria (además del ideal propagandístico augusteo en la lucha contra Antonio). Está igualmente el tema que Octaviano había prohibido a todos los miembros del senado salir de Italia, sin un "permiso o concesión especial". La obligación de los senadores era residir en Roma para limitar su ausencia del Senado.

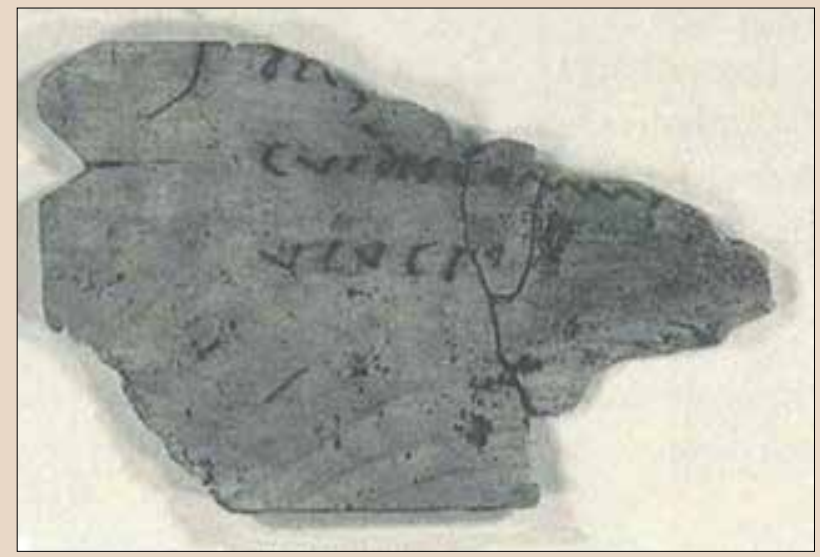

Tableta de Vindolanda, solicitud de permiso de un soldado con el topónimo Ulucia. Fuente: Iglesias Gil y Ruiz Gutiérrez (eds.), 2011.

En el mundo antiguo era más complejo y frágil el problema de identificar a los individuos y, sobre todo, a la "gente de paso" (Milliot, 2007, pp. 2534). Por lo mismo, en la antigua Roma existió una multiculturalidad y una multidimensionalidad de identidades y diferenciaciones que conformaban un todo: una unidad dentro de la diversidad. Esta complejidad en la identificación de las personas tiene mucho que ver con la política integradora y transversal de Roma, de su antiguo lema: plurimae gentes, unus populus (muchas naciones, un solo pueblo); en el fondo, convertir a los peregrini en cives Romani. Una mayor integración y una menor discriminación (Ricci,

${ }^{13}$ Un suceso testimoniado más adelante por Dión Casio, LI, 17, 1. Augusto confió el gobierno de Egipto al prefecto Cornelio Gallo y no a los senadores. 
2005, p. 14); por ello, el mecanismo central de conceder la civitas Romana a los extranjeros se convirtió en el pilar de la integración y longevidad imperial, además de transformarse en un signo de identificación en que todos se puedan reconocer. La trilogía romanidad, ciudadanía e identidad (Inglebert, 2002, pp. 241-260), será la clave para dilucidar qué es ser y sentirse romano, la forma de ser como fenómeno integrado vinculado a todos los miembros de su mundo.

La identificación de ser y considerarse romano se vincula asimismo con una identidad y familiaridad común: su tria nomina ${ }^{14}$. Un romano era reconocido por su lengua, vestimenta, costumbres, inclinaciones e intereses, por ser consciente de su posición privilegiada como ciudadano romano, por un cierto horizonte espiritual debido a su conocimiento de las tradiciones romanas y no tanto por su fortuna económica (Alföldy, 2009, p. 74). Con excepción del cives Romani, no existió una forma precisa y objetiva de identificación; más bien, estas fueron variadas, dependiendo del criterio a utilizar para su autentificación.

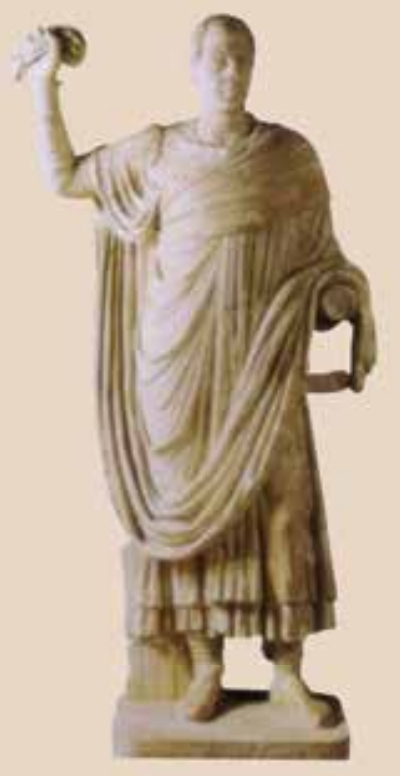

Identificación del ciudadano: su tria nomina y la toga. Estatua de un magistrado de época imperial (Roma, Musei Capitolini).

${ }^{14}$ Identificado con el praenomen (el primer nombre propio desde su nacimiento), el nomen o gentilicium (nombre de la familia) y el cognomen (sobrenombre o la parte final). Ejemplo: Marco Livio Druso; Cayo Julio César. 
En el alto imperio se estructuró gradualmente la unidad imperial, una ciudadanía común, un territorio geográfico centrado en el mare nostrum, una afinidad y unos modos de vida común que constituyeron la manera de vivir como romano material y psicológicamente, indicando una multiplicidad de matices, con una gran diversidad cultural, étnica y social (Todisco, 2005, p. 133). De ahí que la Romanitas ${ }^{15}$ posee un principio y un valor determinante de identidad y de valor universal que significa sentirse partícipe de una misma cultura aunque sea en un extenso imperio. Más aún, la integración será para los romanos un manifiesto de "utilitarismo y pragmatismo", pero por sobre todo, un paradigma de "buen gobierno" (Valditara, 2015, pp. 33-35).

Distinto será el caso en el siglo XIX con la constitución del Estado-Nación, donde se exacerba la raza, la identidad y un patriotismo nacional. En aquellos estados se simplificó y se hicieron más expeditas las formas de cómo identificar a un ciudadano, a un extranjero, a un inmigrante legal o clandestino. La frontera, del mismo modo, se concibe en relación directa con el territorio soberano que debe protegerse y separarse de los otros.

Otro aspecto referente a la identificación dice relación con el tema de las confianzas: ¿Cómo probar que un individuo (un mensajero, embajador, comerciante, militar, funcionario, conferencista, estudiante y muchos otros) que se presenta es realmente quien afirma ser? Se podría hablar de documentos de identidad, como "provisorios" y acotados a una misión y que representa a una persona. Es necesario insistir en la fragilidad y debilidad del proceso de identificación, las falsificaciones y errores tanto en la antigüedad como también sucede actualmente. Por ello es útil acercarnos a la Fisonomía (ciencia que determina el carácter del individuo por las facciones de su rostro); en el fondo, la identidad del alma en los rasgos físicos. Ya Polemón nos señaló: "los signos son testigos"16. Por otra parte, la identificación está ligada al reconocimiento de un estatus, un privilegio, un compromiso y una vestimenta e indumentaria. Apolonio de Tiana en el año 66 d.C. intenta entrar a Roma a la manera de los filósofos (usando el manto de lino), y desafía a Nerón que los había reprimido y expulsado. Los guardias se dieron cuenta y el pitagórico Apolonio fue llevado a prisión.

Se acercaron entonces a las puertas de la ciudad y los guardias no les preguntaron nada; solamente examinaron con asombro sus vestimen-

\footnotetext{
15 Tertuliano, Palio, 4, 1, expresión concebida en calidad de la "manera de pensar y actuar como romanos", en el sentido de una identidad propia y como modelo de sociedad.

${ }^{16}$ Polemón I, 19, 22, “signa... testantur”, citado en Moatti (2007, p. 15).
} 
tas: su aspecto era totalmente religioso, y no se parecía en nada al de los mendigos. Bajaron a un hospedaje cerca de la puerta y estaban cenando, ya que anochecía, una vez que entró, como con la intención de hacer una fiesta, un individuo ebrio, dotado de una voz encantadora (Filóstrato, Vida de Apolonio, IV, 39).

Las fuentes igualmente nos transmiten algunos casos de cómo eran identificados los jóvenes - un problema muy actual- que viajaban y se instalaban en Roma a estudiar. Un ejemplo de la época del emperador Valentiniano I (364-375 d.C.), señala:

Apenas llegados a la Ciudad, (la gente joven) debe ver al magister census y él les entrega el permiso escrito para estudiar, concedido por el gobernador provincial: el archivo debe contener el nombre de su ciudad, un certificado de nacimiento, referencias que acrediten su escolaridad. Los censuales preparan informes anuales del número y el progreso de los estudiantes y envían cada año estos informes al emperador (Código Theodosiano XIV, 9, I).

\section{CONTROLES INTERNOS}

En el espacio imperial romano no existió una disposición general o una norma prohibitiva que impidiera una libre circulación entre una ciudad y otra o entre las diferentes provincias. Las personas se movilizaban abiertamente, no debían pagar "peajes” por transitar en las vías. Solo en un único aspecto necesitaban un control riguroso e interno de los miembros del imperio: el ámbito fiscal. Los mercaderes y comerciantes debían cancelar un impuesto, la quadragesima Galliarum (France, 2001, pp. 205-266), equivalente al 2,5\% del valor de las mercancías que transportaban, sobre todo en la pars Occidentis del imperio (Galia, Germania y provincias alpinas). Este sistema de control y aduana surge con Augusto y en la época de los emperadores Severos se ha extendido al resto del imperio. La quadragesima Galliarum significaba el pago de los productos a comerciar y se entregaba en las oficinas aduaneras respectivas una documentación certificando dicha cancelación. Si bien esta medida era económica en beneficio del Estado, pudo de la misma manera haber desempeñado un rol de control y vigilancia de los individuos, sobre todo, de vagabundos, delincuentes y gente de mala reputación.

Al margen del aspecto fiscal, en el orbe romano no se produjo un sistemático control de identidad de los ciudadanos y miembros del imperio. No 
fue regular y no se aplicaba diariamente, pero tampoco podemos constatar que no hayan existido protocolos y normas de control y seguridad de los individuos. De hecho los hubo a lo largo y ancho de un vasto imperio. Es necesario precisar que aquellos habitantes que cometían algún delito o tenían algún proceso en curso, como también bandidos y prófugos, podían ser detenidos por la autoridad y los controles locales. En la pars Orientis se pueden distinguir dos categorías o fuerzas de fiscalización, los llamados diogmitae: tropa de magistrados municipales, dotados de atribuciones policiales (Brélaz, 2005, pp. 145-158). Su función consistía en limitar la libertad de desplazamiento de aquellas personas con prontuario delictivo, pudiendo arrestar a fugitivos, criminales y bandidos. Eran detenidos bajo las medidas de las autoridades citadinas y dentro de sus autonomías, obviamente bajo el amparo de la autoridad romana. Además de los diogmitae, encontramos en la región del Asia menor a los (h)orophylaques, guardias fronterizos encargados de proteger los límites y eran a su vez policías locales que patrullaban los territorios montañosos, rurales y los confines en las provincias orientales.

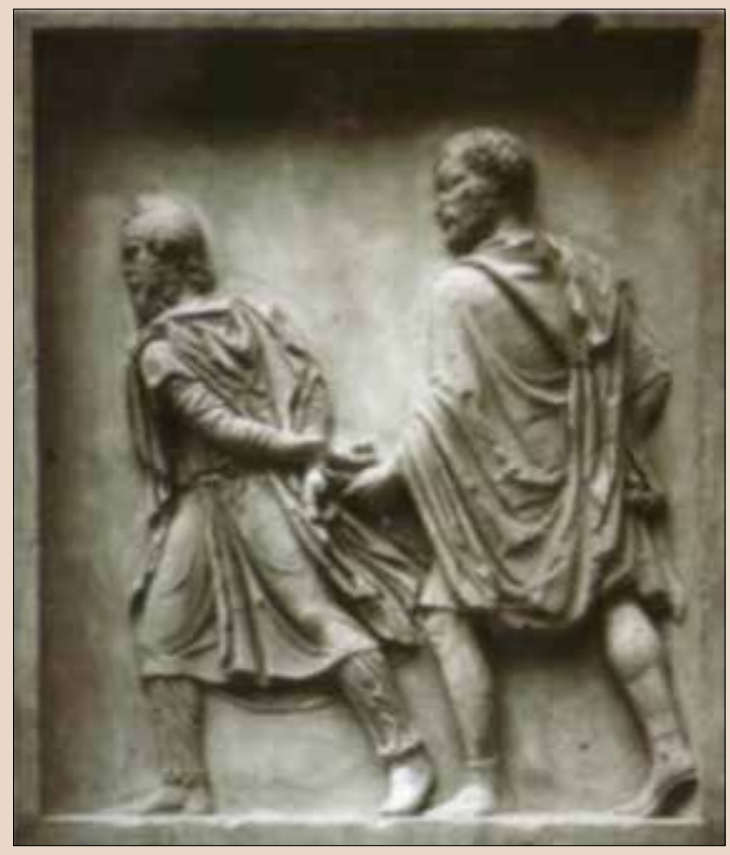

Bárbaro prisionero. Relieve de la base de una columna del arco de Septimio Severo, siglo III d.C. 
En Roma, por su parte, la función de política urbana la ejercieron las cohortes urbanae que aseguraban la tranquilidad y el mantenimiento del orden público (Ramieri, 1996, pp. 28-37). También estaban los stationarii (soldados de guardia), miembros de los grupos urbanos distribuidos en la Urbs, con el propósito de controlar el orden, asegurar la tranquilidad de los habitantes e informar al prefecto de lo que acontecía en la ciudad (Moatti, 2007, p. 83). Asimismo, los frumentarii (soldados legionarios relevantes), a partir de finales del siglo I d.C., llevaron a cabo ciertas misiones de "policía política" que sirvieron para neutralizar a eventuales enemigos y tener un cierto control social (Perea Yébenes, 2013, p. 244). En fin, la tutela urbis con el propósito de resguardar el orden, especialmente diurno, le correspondió al praefectus urbi.

Con frecuencia las fuentes evocan la precaria condición de todos aquellos individuos y extranjeros que entraban por primera vez a Roma ${ }^{17} \mathrm{u}$ otra ciudad relevante. De partida, no gozaban de protección jurídica (podían ser llevados a prisión y sus bienes embargados), sin derecho a defenderse. Con el tiempo esta situación fue cambiando y mejorando, creándose un derecho de las personas (ius gentium), con el fin de remediar los abusos. El imperio romano configuró finalmente un "espacio jurídico" y, por consiguiente, "protegido", donde se circuló libremente (Moatti, 2007, p. 79). Más aún, se acogieron favorablemente a los extranjeros ${ }^{18}$; estos se integraron y obtuvieron gradualmente la civitas Romana (Noy, 2002, p. 286).

\section{ALCANCES FINALES}

Los ejemplos y la experiencia histórica romana nos ilustran sobre la libertad de circulación, de identificación y seguridad de los individuos y de las personas en el espacio romano. Aunque para algunos fue frágil, poco consistente y rudimentario, lo significativo es que contaron -a partir de las escasas fuentes- con un sistema de autenticidad en un imperio mestizo. Hubo control, procedimientos policiales y de identificación que acredi-

\footnotetext{
${ }^{17}$ Distinto será el caso de la entrada a la Urbs de un ciudadano romano, como fue Pablo de Tarso ("el apóstol de los gentiles"). Detenido en Jerusalén, apeló al emperador (Nerón) y fue llevado a Roma para ser juzgado. Ahí arrendó una casa particular custodiada por un soldado (55-56 d.C.). Véase, Hechos de los Apóstoles, 28, 1, 15-16.

${ }^{18}$ El mundo romano fue contrario, en general, a la ley de la xenelesía (que prohibía entrar a los extranjeros). Costumbre mayormente común entre los bárbaros, en calidad de incivilizados y contrarios. Véase, Estrabón, Geografía, XVII, 9.
} 
taban y aseguraban a los integrantes del imperio. La entrada a la ciudad de Roma, cruzar sus murallas, plantea una serie de procesos de reconocimiento y de vigilancia, formalizados abiertamente o realizados en forma implícita ${ }^{19}$. Existieron prohibiciones de entrada, limitaciones de estadía, expulsiones variadas que aseguraron un control e individualización de los miembros del mundo romano. Fue un espacio ciertamente libre y con diversos mecanismos de vigilancia y control social de la población.

Con la conformación del Estado-Nación en los tiempos modernos, se pudo mejorar ostensiblemente el argumento de la identificación de personas. De hecho, el sistema de reconocimiento de las huellas digitales, creado por el polímata británico Francis Galton hacia fines del siglo XIX, fue un gran avance aceptado universalmente. Se debía proteger las fronteras externas y el territorio soberano de posibles enemigos, extranjeros hostiles e inmigrantes. Esta es sí otra historia y la Unión Europea la está padeciendo. Por lo mismo, el modelo romano con similitudes y diferencias, con continuidades y rupturas, nos ayuda para comprender más cabalmente la realidad de la Europa contemporánea.

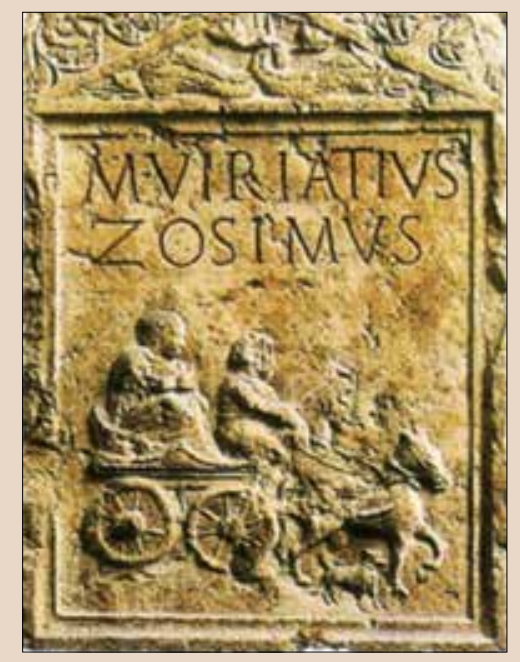

Estela funeraria de M. Viriatius Zosimus, representando un viaje a través del espacio romano (Roma, Museo della civiltà romana).

\footnotetext{
${ }^{19}$ Oficialmente, será a partir de 1608 que en Viena, en cada puerta de la ciudad, dos guardias se encargaban de preguntar su nacionalidad a los inmigrantes. Cfr. Moatti (2007, pp. 92-93.)
} 


\section{REFERENCIAS}

Alföldy, G. (2009). “The Imperium Romanum: A Model for a United Europe?”. En Chaniotis, A., Kuhn, Ch. (eds.), Comparisons, Constructions, Controversies (pp. 57-82). Stuttgart: Heidelberger Althistorische Studien und Epigraphische Beiträge, 46.

Bancalari, A. (2007). Orbe Romano e Imperio Global. La romanización desde Augusto a Caracalla. Santiago: Editorial Universitaria.

Barbero, A. (2006). Barbari. Immigrati, profughi, deportati nell'impero romano. Roma-Bari: Laterza.

Bigo D. (1998). Frontiers and Security of the European Union. En Anderson M., Bort E. (eds.), The Frontiers of Europe (pp. 148-164). London: Pinter.

Brélaz, C. (2005). La sécurité publique en Asie Mineure sous le Principat (I ${ }^{\text {er }}$-III ${ }^{\mathrm{ème}}$ s. ap. J.-C.). Institutions municipales et institutions impériales dans l'Orient romain. Basilea: Schwabe Verlag.

Cerutti, F. y Rudolph, E. (a cura di) (2002). Un 'anima per l'Europa Lessico di un'identità política. Pisa: ETS.

Cracco Ruggini (1993). "Culture in dialogo: La preistoria dell' idea di Europa”. En Schiavone, A. (ed.), Storia di Roma 3, I, L'età tardoantica. I. Crisi e trasformazioni (pp. 351-367). Torino: Einaudi.

Cunliffe, B. (1994). "L'organizzazione della frontiera come fattore di destabilizzazione”. En Guilaine, J. y Settis, S. (eds.), Storia d'Europa, II, Preistoria e Antichità (pp. 1257-1292). Torino: Einaudi.

Dión Casio (2011). Historia romana. Madrid: Gredos.

Elio Aristides (1997). Elogio a Roma. Madrid: Gredos.

Estrabón (2003). Geografía. Madrid: Gredos.

Filóstrato (1992). Vida de Apolonio de Tiana. Madrid: Gredos.

Forni, G. (1988). "Limes: nozioni e nomenclature”. En Sordi, M. (ed.), Il confine nel mondo classico (pp. 272-294). Milano: Contributi dell’ Istituto di Storia Antica, 13, Università Cattolica Sacro Cuore di Milano.

France, J. (2001). Quadragesima Galliarum. L’organisation douanière des provinces alpestres, gauloises et germaniques de l'empire romain. Rome: École française de Rome.

Frézouls, E. (1989). "Déplacements à l'intérieur des provinces occidentales sous le Haut-Empire: quelques exemples". Ktema, 14, 123-138.

Garzetti, A. (1974). From Tiberius to the Antonines. A History of the Roman Empire A.D. 14-192. London: Methuen.

Gayo, C. (2002). Instituciones. Navarra: Aranzadi.

Giardina, A. et Pesando, F. (a cura di). (2012). Roma caput mundi. Una città tra dominio et integrazione. Milano: Electa.

Grant, M. (1994). The Antonines. The Roman Empire in transition. LondonNew York: Routledge.

Herodiano (1986). Historia del imperio romano. Madrid: Gredos. 
Iglesias Gil, J. M. y Ruiz Gutiérrez, A. (eds.) (2011). Viajes y cambios de residencia en el mundo romano. Santander: PubliCan-Ediciones de la Universidad de Cantabria.

Inglebert, H. (2002). "Citoyenneté romaine, romanités et identités romaines sous l'empire”. En Íd. (ed.), Idéologies et valeurs civiques dans le monde romain (Hommage à Claude Lepelley) (pp. 241-260). Paris: Picard.

Lassandro, D. (1986). "L'integrazione romano-barbarica nei panegyrici latini". En Sordi, M. (a cura di), L'Europa nel mondo antico, 1 (pp. 153-159). Milano: Contributi dell' Istituto di Storia Antica, 12, Università Cattolica del Sacro Cuore.

Lassère, J.M. (2006). "La mobilité de la population. Migrations individuelles et collectives dans les provinces occidentales du monde romain”. En Akerras, A., Rugeri, P., Siraj, A., Vismara, C. (eds.), L'Africa Romana. Mobilità delle persone e dei popoli, dinamiche migratory, emigrazioni ed immigrazioni nelle province occidental dell'Impero romano (pp. 57-92). Roma: Carocci.

Le Roux, P. et Tranoy, A. (1987). "La tessera hospitalis, instrument de sociabilité et de romanisation dans la péninsule ibèrique”. En Id (eds.), Sociabilitè, pouvoir et societè (Colloque de Rouen, 1983) (pp. 323-336). Rouen: Actes du Colloque de Rouen. F. Mayet (textes réunis) Itineraria Hispanica. Recueil D' Articles de Robert Étienne, De Boccard, Bordeaux).

Lo Cascio, E. (1995). “Impero e confini nell'età del principato”. En Foresti, L. y otros (eds.), L'Ecumenismo politico nella coscienza dell' occidente (pp. 333350). Alle radici della casa comune europea, vol. II (Bergamo 18-21 settembre 1985). Roma: L'Erma di Bretschneider.

Luttwak, E. (1976). The Grand Strategy of the Roman Empire. From the First Century A.D. to the Third. Baltimore \& London: The Johns Hopkins University.

Luzzatto, G. I. (1985). Roma e le province, I, Organizzazione, Economia, Società. Bologna: Cappelli.

Marco Simón, F., Pina Polo, F., Remesal Rodríguez, J. (eds.) (2004). Vivir en tierra extraña. Emigración e integración cultural en el mundo antiguo. Barcelona: Universitat de Barcelona.

Milliot, V. (2007). "La mobilité des personnes: un laboratoire du contrôle sociale”. En Moatti et Kaiser, Gens de passage en Méditerranée de l'Antiuité à l'époque moderne. Procédures de contrôle et d'identification (pp. 25-34). Paris: Maisonneuve y Larose.

Millar, F. (1977). The Emperor in the Roman World (31 BC-AD 337). London: Duckworth.

. (1993). The Roman Near East 31 BC-AD 337. Cambridge: Mass. \& London.

Moatti, C. (2000/2). "Le contrôle de la mobilité des personnes dans l'Empire Romain”. Mélanges de l'École française de Rome, 112, 925-958.

. (2004). La mobilité des personnes en Méditerranée, de l'Antiquité à l'époque moderne. Procédures de contrôle et documents d'identification. Actes 
de deux colloques tenus à Rome (8-9 mars 2002) et à Paris (la mobilité négociée, 29-30 novembre 2002). Roma: Coll.de l'École française de Rome.

. (2007). "Le contrôle des gens de passage à Rome aux trois premiers siècles de notre ère". En Moatti et Kaiser, Gens de passage en Méditerranée de l'Antiquité à l'époque moderne. Procédures de contrôle et d'identification (pp. 79-114). Paris: Maisonneuve y Larose.

Moatti, C. et Kaiser, W. (dir.) (2007). “Introducción”. En Moatti, C., Gens de passage en Méditerranée de l'Antiquité à l'époque moderne. Procédures de contrôle et d'identification (pp. 9-19). Paris: Maisonneuve y Larose.

Moatti, C., W. Kaiser, Pébarthe, C. (eds.) (2009). Le monde de l'itinérance. Le contrôle de la mobilité des personnes en Méditerranée de l'antiquité à l'époque moderne III. Bordeaux: Ausonius.

Modéran, Y. (2004). L'établissement de Barbares sur le territoire romain à l'époque impériale (Ier-IVe siècle). En Moatti, C., La mobilité des personnes en Méditerranée, de l'Antiquité à l'époque moderne. Procédures de contrôle et documents d'identification. Actes de deux colloques tenus à Rome (8-9 mars 2002) et à Paris (la mobilité négociée, 29-30 novembre 2002) (pp. 337-397). Roma: Coll. de l'École française de Rome.

Noy, D. (2002). Foreigners at Rome. Citiziens and Strangers. London: Duckworth. Pecchi, E. (2013). Senza frontiere. La libera circolazione delle persone in Europa. Bologna: Il Mulino.

Perea Yébenes, S. (2013). Collegia Militaria. Asociaciones militares en el imperio romano. Salamanca: Signifer Libros.

Pseudo Arístide (1996). Discorso all’ imperatore. Milano: Mondadori.

Purpura, G. (2002). "Passaporti romani”. Aegyptus, 82, 131-155.

Ramieri, A.M. (1996). I servizi pubblici. Roma: Quazar.

Ricci, C. (2005). Orbis in Urbe. Fenomeni migratori nella Roma imperiale. Roma: Quasar.

Sordi, M. (ed.) (1994). Emigrazione e inmigrazione nel mondo antico. Milano: Contributi dell'Istituto di storia antica, 20, Università Cattolica del Sacro Cuore.

Tácito (1986). Anales. Madrid: Gredos. . (1988). Germania. Madrid: Gredos.

Tertuliano (2001). Sul anima et Palio. Milano: Mondadori.

Todisco. E. (2005). "L’immigrato e la comunità cittadina: una riflessione sulle dinamiche di integrazione". En Pani. M (a cura di). Storia romana e storia moderna (pp. 133-153). Bari: Edipuglia.

Trousset, P. (1993). "La frontière romaine et ses contradictions". En Romain, Y. (ed.), La frontière. Séminaire de recherche (pp. 25-33). Paris: Maison d'Orient, 21.

Valditara, G. (2015). L'inmigrazione nell' antica Roma: una questione attuale. Catanzaro: Rubbettino. 
Whittaker, C. R. (2000). "Roman frontiers and European perceptions". Journal of Historical Sociology, 13/4, pp. 462-482.

Whittaker, D. (2004). The Use and Abuse of Immigrants in the Later Roman Empire. En Moatti, C. (ed.), La mobilité des personnes en Méditerranée, de l'Antiquité à l'époque moderne. Procédures de contrôle et documents d'identification (pp. 127-153). Roma: Coll. de l'École française de Rome. 